\title{
Anti-ICOS Agonist Antibody GSK3359609
}

National Cancer Institute

\section{Source}

National Cancer Institute. Anti-ICOS Agonist Antibody GSK3359609. NCI Thesaurus. Code C126804.

An agonistic antibody for the inducible T-cell co-stimulator (ICOS; CD278), with potential immune checkpoint inhibitory and antineoplastic activities. Upon administration, anti-ICOS agonist antibody GSK3359609 targets and binds to ICOS expressed on tumor infiltrating CD4-positive T-cells. This stimulates ICOS-positive T-cell proliferation, enhances cytotoxic T-lymphocyte (CTL) survival and increases CT L-mediated immune responses against tumor cells. ICOS, a T-cell specific, CD28-superfamily costimulatory molecule and immune checkpoint protein, is normally expressed on certain activated T-cells and plays a key role in the proliferation and activation of $\mathrm{T}$-cells. 